\title{
The effects of adverse childhood experiences of social work students on notions of well-being: insights for education and practice
}

\author{
Glynnis Dykes and Sulina Green
}

\begin{abstract}
This case study focused on the effects of adverse childhood experiences on undergraduate social work students. The notion of subjective well-being (SWB) was used to frame the findings. The study used 20 reflexive assignments of third year social work students and 10 student interviews in a selected university in South Africa. Three themes centred on the effects of ACEs reflecting students' inner turmoil and externalising behaviours. These effects contrasted with the components of SWB. The implication is that many social work students attend social work classes while still enduring the effects of ACEs. This would imply the possibility that social work students are being trained to intervene in issues evocative of personal experiences which may pose challenges for requisite objectivity. The findings show the need to explore the appropriate social work curriculum, to meet the learning needs of an emerging student profile.
\end{abstract}

\section{INTRODUCTION}

Positive childhood attachment is essential for positive adult adjustment (Hinnen, Sanderman and Sprangers, 2009). People assimilate childhood experiences that revolve around their connections with primary caregivers and give rise to emotional and perceptual images (mental models) which inform their "expectations, perceptions and behaviours throughout life" (Hinnen et al., 2009:11). These images represent the self in association with others and inform the internal working model which is assumed to be the means through which the effects of childhood experiences persist into adulthood. However, because adversity in life is unavoidable, many people experience serious difficulties that result in making them vulnerable to detrimental psycho-social and physical effects (Cohen, Ferguson, Harms, Pooley and Tomlinson, 2011). Research has confirmed a strong relationship between adverse childhood experiences (ACEs) and mental health difficulties in later life (Jovanovic, Blanding, Norrholm, Duncan, Bradley and Ressler, 2009).

According to Felitti and Anda, ACEs include any of the conditions in the family (or household) before the age of 18 years (Brown, Anda, Felitti, Edwards, Malarcher, Croft and Giles, 2010). The main components of ACEs are: frequent child abuse, ineffectual child caregivers, poor family well-being, and unfavourable social environment (Dykes, 2014, 2012; Brown et al., 2010). ACEs can be understood to encompass harmful incidents during childhood which are perceived by a person as negative or traumatising based on the severity 
of the incident and the effects on the person (Dube, Felitti, Dong, Giles and Anda, 2003). As such, ACEs have severe implications for the general well-being (GWB) of individuals because they set progressive effects in motion (see Figure 1). An individual's SWB is a personal and biased account of how she/he perceives and views her/his well-being which can either be positive or negative in terms of cogent and emotional responses (Diener, 2009).

Previous research regarding SWB and social work focused on practitioners rather than on students (Fouche and Martindale, 2011; Graham, Shier, Newberry and Esina, 2014). Research on ACEs and social work was mostly related to general life experiences rather than focusing on the formative childhood years (Schenck, 2009, 2008; Earle, 2008). There seems to have been only limited research done on ACEs and social work students, SWB and social work students, and particularly on the association between ACEs, SWB and social work students. The gap in previous studies is that the impact of ACEs on social work students has not yet been explored.

The purpose of this study is therefore first, to explore and describe the impact of ACEs on social work students, and second, to compare and contrast to SWB. The research question is: What are the effects of ACEs on social work students which may have consequences for their well-being?

Well-being can be viewed through the following conceptual framework that will justify and clarify the research topic and question.

\section{SUBJECTIVE WELL-BEING (SWB)}

SWB is focused on an individual's view of their own well-being. It is centred on the ways that people experience their lives as positive or negative in terms of their rational and The Social emotional responses (Siedlecki, Salthouse, Oishi and Jeswani, 2014; Ratelle, Simard and Guay, 2013). Individuals evaluate the quality of their lives in a variety of ways but the most fundamental way is through the myriad of emotional reactions and experiences throughout the day (Lucas and Diener, 2008). Major life events can have serious implications for SWB, especially on the individual's rational and emotional functioning (Luhmann, Hofmann, Eid and Lucas, 2012). Whether an individual's life evaluation is centred on small or major life events, her/his psychological needs are important bases for SWB (Ratelle et al., 2013). A vital aspect of these needs is the level of interaction and engagement with significant others (family, friends and neighbours), for example, for socio-emotional support (as sources or opportunities for healthy reliance on others for assistance), and for social engagement or integration activities (Siedlecki et al., 2014).

SWB has four components (Marion, Laursen, Zettergren and Bergman, 2013; Saha, Huebner, Hills, Malone and Valois, 2014) namely: 


\section{Life satisfaction (LS)}

The level to which an individual determines their overall or GWB. Significant factors in self-evaluation are intrapersonal factors such as self-concept and self-confidence, as well as the occurrence of stressful life events, their impact, and the coping responses to these events. Coping responses reflect the way in which one's feelings, thoughts, and behaviour is managed in relation to stressful experiences.

\section{Domain satisfaction (DS)}

The level of satisfaction (and worth) within specific areas in an individual's life, such as interpersonal relationships (family/parents, friendships, colleagues, romantic), especially the level of peer acceptance and rejection experienced. Other domain areas include academic, finances, social life and recreation, environment, and health.

\section{Positive affect (PA)}

The extent to which an individual experiences pleasant feelings and moods during the day, pointing to a positive disposition and frame of mind.

\section{Negative affect (NA)}

In contrast to PA, here an individual experiences unpleasant feelings and moods during the day which reflect a pessimistic and depressing disposition and frame of mind.

SWB functions in relation to two subjective evaluative structures. The rational or cognitive structure consists of thinking about or considering if one's life is good and positive regarding LS and DS. The emotional or affective structure consists of the PA and the NA underlying these experiences. LS and DS are strongly related as DS is more likely to influence LS reflecting a particular integrative relationship, where PA and NA are influenced by events in DS but are independent structures, although there is a measure of association (Figure 1) on the following page.

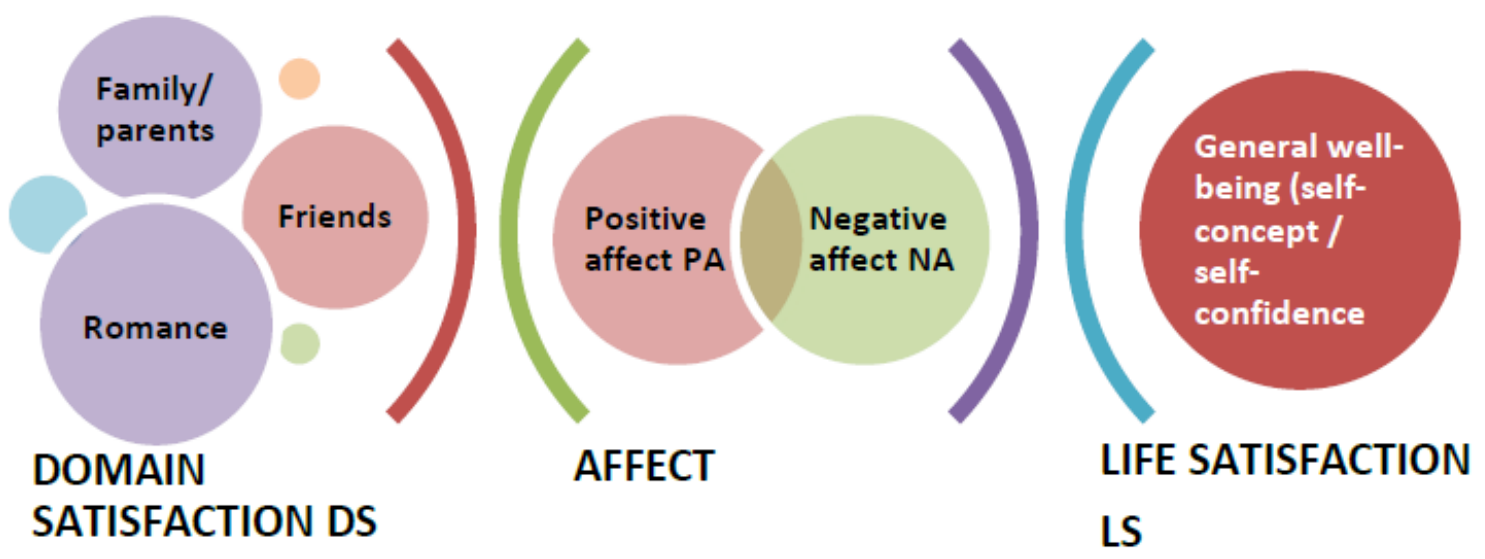

\section{Figure 1: Relational framework of SWB}

(Source: Krueger and Stone, 2014; Siedlecki et al., 2014; Ratelle et al., 2013) 
SWB also has vital implications for educational outcomes for students in higher education as it contributes to the student's self-confidence and self-efficacy, which in turn lead to positive student engagement, class attendance, educational goal attainment, as well as completion and throughput (Ratelle et al., 2013).

\section{RESEARCH METHODOLOGY}

This research followed a qualitative instrumental case study approach because the study focus was on a single case. The study purpose was to explore how individuals (third-year social work students at a selected university in South Africa) experienced a particular phenomenon (in this case ACEs) and the effects of ACEs on their well-being. The data was collected using two methods:

- A reflexive assignment as a formative task in a specific social work module on family well-being. All students were required to respond to seven questions focusing on the kinds of incidents or circumstances that had occurred during their childhood years (from birth to 18 years) which they thought could have had a negative influence on the kind of family life that they had experienced. Thirty reflexive assignments were selected based on purposive sampling. Twenty assignments were used based on the saturation of data.

- Individual interviews with a further sampling of 10 student participants (derived from the sample of reflexive assignments of student participants). Purposive sampling was again used based on inclusion criteria. Participants were selected based on their assignments having incidents of at least two elements in the definition of ACEs. In the interviews participants were asked to expand on their ACEs and the nature of their learning experiences in the social work class.

The site represents the bounded system where the data were collected. In this study, the site represented the third year social work class of mainly first-generation students at a specific university. The university draws students from diverse social backgrounds, often including students from challenging circumstances. In some studies researchers may have personal or professional interests that may cause power imbalances where participants feel coerced by the position of the researcher (for example as their lecturer). To neutralise this, Creswell

(2013) advises that the researcher use multiple sources of information and multiple strategies for validation. The researcher selected four validation strategies to authenticate the process of data collection and data analysis, namely triangulation, member checking, thick, rich descriptions, and researcher reflexivity (Creswell, 2013; Babbie and Mouton, 2007). Thematic analysis is a method of uncovering and classifying common themes in the data and is used to gain understanding of the patterns, forms and configurations of the two data sets (Creswell, 2013; Braun and Clark, 2006). 


\section{KEY FINDINGS: THE EFFECTS OF ADVERSE CHILDHOOD EXPERIENCES (ACEs)}

The findings exemplified the effects of ACEs on participants as a result of the living conditions and circumstances which they endured as children. The data converged into three themes, namely internalising behaviours, externalising behaviours, and low self-esteem.

\section{Theme 1: Internalising behaviours}

In terms of this theme, participants reported internalising behaviours and reactions to their childhood experiences. Liu (2004) confirms that children develop reactions that centre primarily on their inner psychological functioning, such as being withdrawn, anxious, inhibited, and depressed. This theme represents the strongest reaction in the study. Subthemes identified are the following:

Inward feelings and reactions: Participants expressed feelings and reactions which included feeling empty, depressed, repressing feelings, suicide ideation, inhibited communication, as well as shame and embarrassment. Specific extracts attesting to these inward feelings and reactions are presented:

"I've grown up to be someone who tends to be alone all the time. I never let anyone in because I do not know how to communicate and talk about my feelings. I also find it very difficult to get attached to people because I do not want to have to deal with the feelings that occur when they leave. I am scared of being abandoned and I also repress feelings."

"During this time $\underline{I}$ just wished that my life could end. I constantly had thoughts of committing suicide. If not that, I was thinking of experimenting with 'Tik' [crystal methamphetamine] or also just getting wasted with alcohol so that I did not have to witness that."

These narratives show the depth of participants' anguish and distress. Childhood trauma can impact on the individual's self-worth and the ability to see the world as a safe place (Amatya and Barzman, 2012; Kapeleris and Paivio, 2011). Incidents of child abuse are linked to various long-term and damaging effects pertaining to emotional arousal and regulation, which lead to intense feelings of depression, sadness, fear or shame (Bernstein, Measelle, Laurent, Musser and Ablow, 2013; Kapeleris and Paivio, 2011). Importantly, further findings have also linked adult women (as victims of childhood emotional abuse) to enduring emotional arousal in reaction to triggers (Bernstein et al., 2013). Various authors have linked suicide ideation to: family discord (Consoli, Peyre, Speranza, Hassler, Fallisard, Touchette, Cohen, Moro and Révah-Lévy, 2013; King and Merchant, 2008), death or loss of parents (Consoli et al., 2013), child abuse (Shilubane, Ruiter, Van den Bome, Sewpaul, James and Reddy, 2013), low self-esteem and poor social support (Shimshock, Williams and Sullivan, 2011). Participants revealed strong evidence of their inward feelings and reactions, corroborated by substantive cited literature. It is clear that ACEs have had a severe and enduring impact on the emotional health of participants. 
Outward feelings and reactions: Participants' reactions included feeling anger and hatred towards significant others like parents, as well as envying and mistrusting others.

"I grew up resenting my mother and blamed her for my painful childhood."

"I used to hate my stepfather before he came into our family, yes we were poor, but my mother and I were at peace and we loved each other."

"I ended up hating my father, at the same fearing him. There was no longer that love and bond of father and child. We were just like enemies staying in the same house."

Here participants expressed their intense (negative) feelings towards significant others. In previous studies, childhood trauma was found to have led to insufficient regulation of emotions such as impulsivity and anger control (Jackson, Kuppens, Sheeber and Allen, 2011; Kapeleris and Paivio, 2011). Additionally, family experiences were identified as key factors in igniting anger and hostility in teens (Muris, Meesters, Morren and Moorman, 2004). Outward behaviour is directed externally towards others. As such, the person's internal locus of control is of importance as this will regulate emotions and reactions. The emotions are also constantly threatened by environmental triggers. The participants showed their vulnerability in this regard through negative feelings such as anger and hatred.

Socio-emotional isolation: These reactions included participants isolating and withdrawing themselves from significant others and becoming socially distant. Examples of student participants' socio-emotional isolation follow.

"When I partake in activities at church I kept my distance and did not allow anyone to become close to me I used defense mechanism to keep my distance."

“That's why I always keep a distance from people, I don't like to build relationships because of that" [referring to incidents of sexual abuse by brother].

"I didn't have any other sisters or brothers so being abused by him made me think that I can't trust anyone and therefore I always try to keep my distance from people even with anyone especially male persons, I just let them like a certain extent allow them close but then I just drop them out and I refrain myself from getting to someone."

Participants have shown their feelings and behaviours as unconscious responses to their traumatic experiences. The hallmark of adolescence is the search for social connections with one's peers and thus the opposite need for social isolation reflects sadness and emptiness (Hall-Lande, Eisenberg, Christenson and Neumark-Sztainer, 2007; Newman, Lohman and Newman, 2007). Research supports the link between physical abuse and social isolation that occurs as a result of impairment of social skills and self-esteem (Elliot, Cunningham, Linder, Colangelo and Gross, 2005). Social isolation has also been identified as an emotional theme of adolescent suicidal experiences (Hall-Lande et al., 2007). The 
significant part of these findings is that there is a conflicting need, for youth in particular, to withdraw from their peers. Cited literature has expounded on this tendency (in the context of ACEs), which has serious implications for the individual's sense of self-worth and value to others. Thus, repercussions of feelings of hopelessness and insignificance are precursors to suicidal ideation and attempts at suicide. Without appropriate intervention, these depressive feelings may well continue to be insidious in the person's life.

Emotional insecurity: The insecurities of participants encompassed the struggles for appreciation and regard as well as self-preservation, through pretence and efforts to create emotionally safe hideouts. The following epitomises students' emotional insecurities:

"I pretend. I felt like I was pretending the whole time ... To be someone I'm not."

"When I just want that time just to be by myself then just let me be or just to deal ... I live there and when you do things to hurt me it doesn't bother me anymore because I'm now comfortable being there" [describing a mental not physical retreat].

Here, participants reflected on how they would emotionally cope when their trauma became untenable for them. Studies support the link between marital conflict and emotional insecurity of children that further indicates difficulties in children's social skills (Cummings George, McCoy and Davies, 2012; Davies, Cicchetti and Martin, 2012). Emotional avoidance, dissociation (pretending) and coping strategies, such as emotional disengagement, are linked with post-traumatic stress (Thompson, Arnkoff and Glass, 2011). The second narrative provided an insider view of an emotionally safe haven to which the participant mentally withdraws when the need arises. The depth of feelings in these narratives is significant and the overwhelming desire to be alone or to pretend is substantiated by the cited literature. These experiences offer insight into the emotional well-being of certain participants.

Distrusting men: Participants (both genders) disclosed their feelings relating to men and gender in terms of distrusting men, believing that men were in control, and in terms of being submissive as a female in future relationships.

"I find it difficult to trust males because my father disappointed me the way he did, when he was drinking."

"I have learnt that I do not want to be dependent on my husband when I get married, maybe I do not trust men."

"I was made to believe that women are powerless individuals who should always be submissive to male authority whereas male members have unquestionable authority in the house." 
These narratives show how participants' ACEs have negatively affected the ways in which they perceive the role of men in their lives. Previous studies have shown that a key indicator for the prevalence of mistrust of men was childhood emotional abuse (Berzenski and Yates, 2010; Riggs, 2010). This prevalence was linked to the extent of abandonment and attachment anxiety experienced that increased defensive behaviours towards men in particularly (Riggs, 2010; Sandberg, Suess and Heaton, 2010); and viewing them (men) through a subjective lens as untrustworthy and weak (Riggs, 2010). In contrast, some studies have found no evidence of the role of childhood experiences in patriarchal beliefs, but have identified existing patriarchal beliefs (by men and women) as key in the prevalence of the dominant role of men (Haj-Yahia, 2005; Lichter and McCloskey, 2004). These findings were verified in cited literature.

Internalising behaviours (theme 1) revealed the inner turmoil of the participants reflecting their inward and outward feelings and reactions, their socio-emotional withdrawal and emotional insecurities. Participants' internalising behaviours were strongly linked to the turmoil they had endured in their childhood.

\section{Theme 2: Externalising behaviours}

There is an interactive relationship (co-morbidity) between internalising and externalising behaviours, where the latter typifies a set of behaviours exhibited through outward actions that show the child negatively acting out within an external setting (Liu, 2004). Research findings confirm that externalising behaviour commonly occurs when a child endures frequent rejection (Laird, Jordan, Dodge, Petit and Bates, 2001). This theme translates into three subthemes as follows:

Behavioural and physical reactions: Participants' reactions included aggression and violence, insomnia, or suicide attempts. Specific excerpts by student participants are presented below.

"I can honestly say I behaved violently... I was like most of the times I was always in conflict with the school authorities."

"Most of the time I struggled to fall asleep."

"At a stage I drank an overdose of tablets to end my life."

Participants described their reactions to their traumatic home circumstances. Studies have linked parental physical abuse to childhood aggression (Gershoff, 2002). Research has also found a strong association between violence and living in under-resourced communities and being involved with negative peer groups (Herrenkohl, Hill, Chung, Guo, Abbott and Hawkins, 2003). Florence and Koch (2011) confirm that the onset of substance abuse by adolescents is attributable to unstable family life or parents who abused substances, and as a result experienced reduced emotional well-being and quality of life (also see Beyers, Bates, Pettit and Dodge, 2003). A study by Bader, Schafer, Schenkel, Nissen and Schwander 
(2007) confirmed a strong link between ACEs and primary insomnia in adults, as well as between ACEs and substance abuse, suicide attempts and emotional disorders (also see Anda, Felitti, Bremner, Walker, Whitfield, Perry, Dube and Giles, 2006). Participants disclosed many examples of their behavioural and physical reactions to ACEs, as referred to in the literature, and exposed the types of physical reactions that they were enduring into adulthood.

Rebellious behaviour: Participants described thwarting household rules, associating with negative peer groups, committing petty crimes, experimenting with substances, and involvement in physical conflicts. Examples are the following:

"I became a rebellious teenager to my mother. I would come home late or not come at all. Go to parties without her approval."

"I ended up with the wrong group of friends, committed small crimes like stealing."

"I started to identify with the wrong peers and got involved with smoking marijuana and my school performance reduced."

Adolescence is typified by parent-child conflict, emotional eruptions, mood swings and rebellion (Cavendish, Montague, Enders and Diaz, 2014; Hollenstein and Lougheed, 2013). Adolescents participate in risk-taking behaviour in order to establish an identity, autonomy and membership with their peer group (Cavendish et al., 2014). Studies have also established a strong link between risk-taking and peer group conformist behaviour (Balsa, Horner, French and Norton, 2011). Western society expects teenagers to be rebellious as part of the modern rituals of maturation and therefore rebelliousness does not necessarily need over-analysis. It is only when these behaviours continue beyond adolescence and take on far more serious overtones that there may be implications for their later well-being. The literature thus explicates the link between rebelliousness, family conflict, and the upheavals of adolescence.

Judgement and choices: Participants revealed adolescent choices they regretted in terms of being sexually explicit, early marriage (to escape the house), emulating violent behaviour, early pregnancy, and dropping out of school. The following are examples of participants' inadvertent judgements and choices:

"So I think that is also one of the reasons why I went out to look for a male person to show me some affection at a young age."

"I wanted to get married because I wanted to get out."

"I was always with guys and I enjoyed the fact that they loved and appreciated me, unlike my father." 
Steinberg (2005) confirms that decision-making in adolescence is complex because of the discord between the developing maturity of the brain and behavioural and cognitive processes (see also Reyna and Farley, 2006). Although Reyna and Farley (2006) stress that adolescents are capable of decision-making under specific conditions, in the main, "adolescents react rather than decide" (Reyna and Farley, 2006:6). Generally, the typical reasons for early school dropout are family-related such as: parental caregiving (Blondal and Adalbjarnardottir, 2009; Englund, Egeland and Collins, 2008), teacher-child relationship, and poor academic achievement (Englund et al., 2008). The findings of the study demonstrated the dire implications for the future of the participants for the choices they were compelled to make. These decisions revealed reactions to family circumstances, rather than rational decision-making, as explained in the literature.

Externalising behaviour (theme 2) represents the behaviours of participants that were expressed outwardly as physical reactions and behaviours. These reactions were also strongly associated with poor family life and childhood abuse.

\section{Theme 3: Low self-esteem}

Participants reflected on experiences that gave rise to their low self-esteem. Self-esteem is an emotional and behavioural expression of one's self-worth derived from the regard from significant others, and the perceptions about one's own beliefs, appearance, emotions and behaviour (McClure, Transki and Sargent, 2010). Low self-esteem is related to externalising behaviours such as: aggression and disordered eating (Paxton, Neumark-Sztainer, Hannan and Eisenberg, 2006), substance abuse and criminal acts (Trzesniewski,

Donnellan, Moffitt, Robins, Poulton and Caspi, 2006), and suicide (Donnellan, Trzesniewski, Robins, Moffitt and Caspi, 2005), as well as internalising behaviour such as depression (Orth, Robins and Roberts, 2008), anxiety (McClure et al., 2010) and suicide ideation (McGee and Williams, 2000). Two categories provided insight regarding participants' self-esteem, namely:

Social shyness and inhibition: Shyness and inhibition resulted in the participants showing unassertiveness, social reticence, and social disconnection. The following are examples of these behaviours:

"I like being on my own ... I'm not very outspoken. I didn't want people in my space. I think I was very closed off and I would only open to my best friend which was one or two people."

"I could never speak out for myself. When he started talking I froze because I knew that I must just listen and keep quiet." 
"I could no longer keep up with other children as far as clothes is concerned which resulted in me becoming anti-social."

These excerpts show participants' social trepidation and their lack of personal power wrought by their experiences. Shyness is viewed as an emotional state because it can be transitive and adaptive to change (Henderson, Zimbardo and Carducci, 2010). Shyness (and inhibition) can also be identified as a risk factor for social anxiety problems (Rubin, Coplan and Bowker, 2009). Research confirms the link between shyness and inhibition and the triggering of fear (Fox, Henderson, Marshall, Nichols and Ghera, 2005). During adolescence, shyness can exacerbate relationship difficulties, especially with peers and school, and can lead to academic truancy (Rubin et al., 2009). Specific causal factors are parenting styles and maternal stress, negative peer relationships and internalising problems (Neal and Edelman, 2003). The cited literature has revealed participants' shyness and inhibitions as being not only located in parenting styles, but that family circumstances and poverty also have roles to play. All of these factors resulted in social anxiety and fear, as cited.

Poor self-efficacy: Self-efficacy centres on beliefs about one's competencies and worth and these beliefs set the "foundation of human motivation, well-being and accomplishments" (Bandura, 2006:3). Ultimately, self-efficacy influences whether one thinks positively or negatively about oneself (Bandura, 2006). Poor self-belief of participants was characterised by feeling undeserving of happiness, feeling stupid (despite scholastic success), and unattractive. The following are examples of self-efficacy:

"My friends were warned to stay away from me because of my brother's doings and I felt isolated, useless and a person of low importance."

"For the longest time I believed that I was stupid, ugly, unworthy and a lot of other synonyms that would easily fit this depiction."

"Throughout childhood my self-esteem and confidence was wrecked. At school I did not have faith in myself. I would not participate in sports and school activities. Because I believed I sucked and was a loser."

These narratives show how participants viewed themselves and what their capabilities were. The link with self-efficacy has been established as a vital motivation for learning (Alivernini and Lucidi, 2011). The literature has confirmed that poor self-efficacy is reflected through thoughts of poor self-worth and poor mastery (Bandura, 2006; Caprara and Steca, 2006). The findings show that these thoughts are a consequence of a negative and rejecting home environment. Although the participants had progressed academically, the pervasiveness of poor self-efficacy still existed internally.

Low self-esteem (theme 3) further revealed the inward feelings of diminished self-worth typically reflected in low self-esteem. The two categories deconstructed this feeling in 
participants, disclosing their shyness and inhibition and their sense of poor self-efficacy. This theme was also a strong indicator of the childhood adversity of the participants.

\section{CONCLUSION AND RECOMMENDATIONS}

The findings produced three themes regarding the impact of ACEs on social work students. These findings provided clarity regarding the effects of childhood abuse, ineffectual caregivers and troubled family life on the participants as children, specifically on their emotional, behavioural, physical functioning and well-being during a significant phase of development and growth. These are important themes, because of the understanding the findings provided of the extent and severity of the impact of ACEs on participants. It can be concluded that the effects of ACEs upon the individual's well-being are varied and longlasting, causing emotional, behavioural and physical difficulties. Consequently there is a strong relation between the ACEs of social work student participants to SWB, essentially because the perceptions and experiences are subjective and thus are personal to the participants. The correlation between ACEs was particular to three components of SWB as shown in the following analysis:

In terms of $\boldsymbol{D S}$, participants negatively evaluated the quality of their life based on childhood abuses and their distressing family life experiences and caregiving received, which influenced the following domains:

- family (for example, disrupted family life and roles where children became caregivers, death of significant caregivers, and where families had to split up);

- friendships (for example, socio-emotional isolation and withdrawal from interpersonal and social relationships, engaging in negative behaviour such as using alcohol, Tik, and dagga; and becoming involved in a negative peer group);

- academic (for example, dropping out of school);

- romantic (for example, making unfortunate choices such as early marriage and sexually explicit behaviour);

- $\quad$ health (for example, suicide attempts; insomnia);

- finances (for example, insufficient income for family's needs or related to an absent father).

Participants' $\mathbf{N A}$ reflected the following:

- inner emotions and moods through depression, suicidal ideations, shame, embarrassment;

- outward feelings such as anger and resentment especially towards their parents;

- emotional insecurity and low self-esteem (and negative self-image) especially inhibited communication about feelings or with others; abandonment fears, general anxiety; repressed feelings.

$\boldsymbol{L} \boldsymbol{S}$ was explicated by the effects of participants' childhood experiences on themselves in terms of their self-worth and ultimately their evaluation of feeling unworthy of happiness. 
It can be concluded that the association between SWB and the findings relating to social work students' ACEs have confirmed the components of SWB into an associative relationship or processional perspective as illustrated in Figure 1. NA was strongly influenced by the events in the domain components and that these ultimately influenced the quality of life for the participants. The research findings have only elucidated the three components above as a direct result of the research question. The findings do not suggest that the participants did not experience any PA.

The conclusion is that the negative impact of ACEs as shown through the analysis of SWB has shown that social work students continue to struggle with the effects of childhood adversity. This confirms that their intense emotional and behavioural struggles have continued in the social work class because the teaching focus is on the very issues that they struggle with. Although these findings pertain to South Africa, they do focus on the kinds of issues that could beset social work students everywhere. The implication for all social work lecturers is that they can no longer ignore remain oblivious to the decisive role these struggles play in the professional learning of students of social work and other helping professions. Further implications point to a rethink of social work curricula and of teaching and learning within the context of professional learning.

Teaching and learning recommendations for social work curricula should include: (i) the professional use of self: students learn to view their prior experiences as strengths and therefore, learning areas should allow opportunities for ways of appropriately using their personal experiences. Wylie (2003) refers to this kind of knowledge as "epistemic privilege" in her discussion of Standpoint Theory (which proposes that those who are subjected to structural domination and oppression may have a knowledge advantage by virtue of their 'position' and experiences). Debriefing, self-awareness, self-reflexivity, countertransference exercises should be standard practice in social work curricula; and (ii) incorporation of modern psychodynamic theories and strengths approaches into curricula: students learn that theories are not only out there (disassociation) but related to people's (and their own) experiences (association) that develop coherent and increased understanding. Relevant theories, discussions, case studies and formative tasks should be selected that illustrate their juxtaposition between theoretical frameworks, people's personal experiences and social work knowledge.

Future conversations and research therefore, should focus on notions of vicarious traumatisation, self-awareness (mindfulness practices), and counter-transference. 


\section{References}

Alivernini, F. and Lucidi, F. (2011). "Relationship between Social Contexts, Self-efficacy, Motivation, Academic Achievement, and Intention to Drop out of High School: A Longitudinal Study" The Journal of Educational Research 104(4):241-252.

Amatya, P. and Barzman, D. (2012). "The Missing Link Between Juvenile Delinquency and Pediatric Posttraumatic Stress Disorder: An Attachment Theory Lens" ISRN (International Scholarly Research Network) Pediatrics (2012) Article ID134541:1-6.

Anda, R., Felitti, V., Bremner, J., Walker, J., Whitfield, C., Perry, B., Dube, S. and Giles, W. (2006). "The Enduring Effects of Abuse and Related Adverse Experiences in Childhood. A Convergence of Evidence from Neurobiology an Epidemiology" European Archives of Psychiatry and Clinical Neuroscience 256(3):174-186.

Babbie, E. and Mouton, J. (2007). The Practice of Social Research Cape Town: Oxford University Press, SA Edition.

Bader, K., Schafer, V., Schenkel, M., Nissen, L. and Schwander, J. (2007). "Adverse Childhood Experiences Associated with Sleep in Primary Insomnia" Journal of Sleep Research 16(3):285-296.

Balsa, A., Horner, J., French, M. and Norton, E. (2011). "Alcohol Use and Popularity: Social Payoffs from Conforming to Peers' Behavior" Journal of Research on Adolescence 21(3):559-568.

Bandura, A. (2006). "Adolescent Development from an Agentic Perspective" in Pajares, F. and Urdan, T. (Eds.). Self-efficacy Beliefs of Adolescents. A Volume in Adolescence and Education Connecticut, USA: Information Age Publishing, 1-43.

Bernstein, R., Measelle, J., Laurent, H., Musser, E. and Ablow, J. (2013). "Sticks and Stones May Break my Bones but Words Relate to Adult Physiology? Child Abuse Experience and Women's Sympathetic Nervous System Response while Self-Reporting Trauma" Journal of Aggression, Maltreatment and Trauma 22(10):1117-1136.

Berzenski, S. and Yates, T. (2010). "A Developmental Process Analysis of the Contribution of Childhood Emotional Abuse to Relationship Violence" Journal of Aggression, Maltreatment and Trauma 19(2):180-203.

Beyers, J., Bates, J., Pettit, G. and Dodge, K. (2003). "Neighbourhood Structure, Parenting Processes, and the Development of Youth's Externalizing Behaviors: A Multilevel Analysis" American Journal of Community Psychology 31(1-2):35-53.

Blondal, K. and Adalbjarnardottir, S. (2009). "Parenting Practices and School Dropout: A Longitudinal Study" Family Therapy 36(3):125-145. 
Braun, V. and Clarke, V. (2006). "Using Thematic Analysis in Psychology" Qualitative Research in Psychology 3(2):77-101.

Brown, D., Anda, R., Felitti, V., Edwards, V., Malarcher, A., Croft, J. and Giles, W. (2010). "Adverse Childhood Experiences are Associated with the Risk of Lung Cancer:

A Prospective Cohort Study" BMC Public Health, 10(20), www.bio-medcentral.com/14712458/10/20 (Accessed on 1/10/2010).

Caprara, G. and Steca, P. (2006). "The Contribution of Self-Regulatory Efficacy Beliefs in Managing Affect and Family Relationships to Positive Thinking and Hedonic Balance" Journal of Social and Clinical Psychology 25(6):603-627.

Cavendish, W., Montague, M., Enders, C. and Diaz, S. (2014). "Mothers' and Adolescents' Perceptions of Family Environment and Adolescent Social-Emotional Functioning" Journal of Child and Family Studies 23:52-66.

Cohen, L., Ferguson, C., Harms, C., Pooley, J. and Tomlinson, S. (2011). "Family Systems and Mental Health Issues: A Resilience Approach" Journal of Social Work Practice 25(1):109125 .

Consoli, A., Peyre, H., Speranza, M., Hassler, C., Fallisard, B., Touchette, E., Cohen, D., Moro, M and Révah-Lévy, A. (2013). "Suicidal Behaviors in Depressed Adolescents: Role of Perceived Relationships in the Family" Child and Adolescent Psychiatry and Mental Health 7:8-20.

Creswell, J. (2013). Qualitative Inquiry and Research Design: Choosing Among Five Approaches Thousand Oaks, CA: Sage, Third Edition.

Cummings, E., George, M., McCoy, K. and Davies, P. (2012). "Interparental Conflict in Kindergarten and Adolescent Adjustment: Prospective Investigation of Emotional Security as an Explanatory Mechanism" Child development 83(5):1703-1715.

Davies, P., Cicchetti, D. and Martin, M. (2012). "Toward Greater Specificity in Identifying Associations among Interparental Aggression, Child Emotional Reactivity to Conflict, and Child Problems" Child Development 83(5):1789-1804.

Diener, E. (2009). "Subjective Well-being" in Eid, M. and Larsen, R. (Eds.). The Science of Well-Being Netherlands: Springer, 11-58.

Donnellan, M., Trzesniewski, K., Robins, R., Moffitt, T. and Caspi, A. (2005). "Low SelfEsteem is Related to Aggression, Anti-Social Behavior and Delinquency" Psychological Science 16(4):328-335. 
Dube, S., Felitti, V., Dong, M., Giles, W. and Anda, R. (2003). The Impact of Adverse Childhood Experiences on Health Problems: Evidence from Four Birth Cohorts Dating Back to 1900" Preventive Medicine 37(3):268-277.

Dykes, G. (2012). "Phronesis and Adverse Childhood Experiences of Social Work Students" The Social Work Practitioner-Researcher 24(3):331-348.

Dykes, G. (2014). An Inquiry into the Role of Adverse Childhood Experiences on Teaching and Learning in Social Work (Unpublished Doctoral Thesis) Stellenbosch University, Social Work Department.

Earle, N. (2008). Social Work in Social Change: The Profession and Education of Social Workers in South Africa Cape Town: HSRC.

Elliot, G., Cunningham, S., Linder, M., Colangelo, M. and Gross, M. (2005). "Child Physical Abuse and Self-Perceived Social Isolation among Adolescents" Journal of Interpersonal Violence 20(12):1663-1684.

Englund, M., Egeland, B. and Collins, W. (2008). "Exceptions to High School Dropout Predictions in a Low-Income Sample: Do Adults Make a Difference?” Journal of Social Work 64(1):77-94.

Florence, M. and Koch, E. (2011). "The Difference between Adolescent Users and NonUsers of Addictive Substances in a Low Socio Economic Status Community: Contextual Factors Explored from the Perspective of Subjective Well-Being" South African Journal of Psychology 41(4):477-487.

Fouche, C. and Martindale, K. (2011). "Work-life Balance: Practitioner Well-Being in the Social Work Education" Social Work Education 30(6):675-685.

Fox, N., Henderson, H., Marshall, P., Nichols, K. and Ghera, M. (2005). "Behavior Within a Developmental Framework" Annual Review of Psychology 56:235-261.

Gershoff, E. (2002). Corporal Punishment by Parents and Associated Child Behaviors and Experience: A Meta-Analytic and Theoretical Review" Psychology Bulletin 128(4): 539579 .

Graham, J., Shier, M., Newberry, A. and Esina, E. (2014). "Aligning Perspectives of Subjective Well-Being: Comparing Spouse and Colleague Perceptions of Social Worker Happiness" The Qualitative Report 19(46):1-18.

Haj-Yahia, M. (2005). "Can People's Patriarchal Ideology Predict their Beliefs about Wife Abuse? The Case of Jordanian Men” Journal of Community Psychology 33(5):545-567. 
Hall-Lande, J., Eisenberg, M., Christenson, S. and Neumark-Sztainer, D. (2007). "Social Isolation, Psychological Health, and Protective Factors in Adolescence" Adolescence 42(166):265-286.

Henderson, L., Zimbardo, P. and Carducci, B. (2010). "Shyness" Corsini Encyclopedia of Psychology 1-3.

Herrenkohl, T., Hill, K., Chung, I., Guo, J., Abbott, R. and Hawkins, J. (2003). "Protective Factors Against Serious Violent Behavior in Adolescence: A Prospective Study of Aggressive Children" Social Work Research 27(3):179-191.

Hinnen, C., Sanderman, R. and Sprangers, M. (2009). "Adult Attachment as Mediator between Recollections of Childhood and Satisfaction with Life" Clinical Psychology and Psychotherapy 16(1):10-21.

Hollenstein, T. and Lougheed, J. (2013). "Beyond Storm and Stress: Typicality, Transactions, Timing, and Temperament to Account for Adolescent Change" American Psychologist 68(6):444-454. 